\title{
CAPITAL INCOME TAXATION AND LONG RUN GROWTH: NEW PERSPECTIVES
}

\author{
Assaf Razin \\ Chi-Wa Yuen
}

Working Paper No. 5028

\author{
NATIONAL BUREAU OF ECONOMIC RESEARCH \\ 1050 Massachusetts Avenue \\ Cambridge, MA 02138 \\ February 1995
}

This paper is part of NBER's research programs in International Finance and Macroeconomics and Public Economics. Any opinions expressed are those of the authors and not those of the National Bureau of Economic Research.

(C) 1995 by Assaf Razin and Chi-Wa Yuen. All rights reserved. Short sections of text, not to exceed two paragraphs, may be quoted without explicit permission provided that full credit, including $\odot$ notice, is given to the source. 


\title{
CAPITAL INCOME TAXATION AND LONG RUN GROWTH: NEW PERSPECTIVES
}

\begin{abstract}
We study the effects of capital income taxation on long run growth in an endogenous growth framework with two distinguishing features: endogenous population and international capital mobility. Endogenizing population growth introduces a new channel for taxes to affect economic growth and enables us to discriminate the effects of taxes on total versus per capita income growth. Allowing for capital mobility in the open economy, we show how the effects of taxes on population growth and income growth across countries will vary in specific ways, depending on the international income tax regimes and the relative preference bias of people towards the 'quantity' and 'quality' of children. The numerical results based on our calibrated model for the G-7 also indicate that, although the effects of liberalizing capital flows on long run growth may not be very sizable, the growth effects of changes in capital income tax rates can be tremendously magnified by cross-border capital flows and cross-border spillovers of policy effects.
\end{abstract}

Assaf Razin

Eitan Berglas School of Economics

Tel Aviv University

Ramat Aviv

Tel Aviv 69978

ISRAEL

and NBER
Chi-Wa Yuen

Department of Finance

Hong Kong University of Science and Technology

Clear Water Bay, Kowloon

HONG KONG 


\section{Introduction}

The effect of capital income taxation on capital accumulation and growth has been a widely studied topic. In the Swan-Solow-type growth models with fixed savings rates, capital income is a pure rent, which can be taxed without affecting capital formation. Empirically, the savings rates have been remarkably stable, either because their interest elasticities are low or because the entire vector of current and future expected returns on which the saving rates depend has been relatively stable. Given the relative constancy of the savings rates, it was thus believed that the impact of capital taxation on accumulation and growth should not cause any immediate concern.

In the late 1970s, this view was challenged by Feldstein (1978) and Boskin (1978), who argue that capital income taxation can have significant effects on the accumulation of physical capital. In the 1980s, Chamley (1981) and Judd (1987) also show that capital taxation has detrimental effects on capital formation in the Cass-Koopmans-type dynasty growth models. Parallelly, Summers (1981) and Auerbach and Kotlikoff (1987) have found similar effects in overlapping generations models.

These studies were confined to the exogenous growth framework. There, the effects of taxes on growth, if any, are transitory. In the long run, only level changes will occur. Using the language of the new growth theory, tax changes only have level effects, but no growth effects. In models of endogenously sustainable growth, Lucas (1990) and Rebelo (1991) have shown that capital income taxes have adverse effects on long run growth rates as well. In the Lucas calibrated model, the growth effects are found to be small. Much bigger effects are found by King and Rebelo (1990). 
Although recent advances in endogenous growth theories have opened up the possibility of analyzing the level and growth effects of various policy changes in both the short and long runs, two important elements have been ignored in the policy-growth studies. They assume exogenous population growth and closed economies.

When population growth is exogenous, capital taxation can only affect income growth through the growth engine (human capital in most studies), with identical effects on the growth of per capita income and total income. Endogenizing population growth will introduce a new channel through which taxes can affect per capita income growth and total income growth differently. Indeed, the paper shows how crucial a difference this assumption can make for the tax-growth relation.

Given the global integration of capital markets, the closed economy assumption does not match the reality very well, thus limiting the quantitative assessment of the tax effects on growth. Opening economies to free capital flows will lead to cross-border spillovers of tax effects, with changes in capital taxes in one country having an impact on the resource allocation in another country. In particular, we would like to examine how the tax-driven growth effects will be affected by open economy considerations.

The paper is organized as follows. Section II describes our theoretical framework in a closed economy, and compares the growth effects of taxes between exogenous and endogenous population. Section III extends the framework to an open economy setting, and assesses the effects of the international tax regimes on the convergence/divergence in the growth of population and income across countries. Section IV uses calibration and simulation methods to evaluate quantitatively the growth effects of capital tax changes in 
both the closed and open economies. Section V concludes.

\section{Closed Economy}

We assume a dynastic economy with $N_{t}$ identical individuals in each period $(t=$ $0,1,2, \ldots)$. The growth process in this economy is driven by the accumulation of physical capital and human capital. The growth of population will be treated both exogenously and endogenously. The representative agent cares about his own consumption $c_{t}$ and the population at large $N_{t}$. To keep the analysis tractable, preferences of the dynastic head of the representative family are assumed to be isoelastic:

$$
\sum_{t=0}^{\infty} \beta^{t} N_{t}^{\xi}\left(\frac{c_{t}^{1-\sigma}}{1-\sigma}\right)
$$

where $\beta$ is the subjective discount factor, $\xi$ an altruism parameter, and $\sigma$ the inverse of the intertemporal elasticity of substitution in consumption. As long as $\xi>0$, altruism is reflected not only in preference for 'quantity', but also 'quality' (as measured by their living standard in terms of consumption per capita), of children-since, with positive $\xi$, there is weight given to quantity, but the weight on the consumption term is magnified as well. Observe that if $\xi>1-\sigma$, then there will be a relative bias in preference towards quantity; whereas if $\xi<1-\sigma$, the bias will be in the opposite direction.

In each period $t$, there are $N_{t}$ members in the representative household (given $N_{0}$ at $t=0$ ). Each household member is endowed with one unit of time (net of leisure, assumed to be perfectly inelastic) and possesses $h_{t}$ of human capital and $k_{t}$ of physical capital carried over from period $t-1$ (given $h_{0}$ and $k_{0}$ at $t=0$ ) in each period $t$. He/she can split the unit 
time among three time-consuming activities-working ( $n_{1}$ for number of worked hours), learning in schools ( $e_{t}$ for education), and child-rearing ( $v_{t}$ for vitality). As we shall see later on, child-rearing, which is the driving force for population growth, will be an essential element in our analysis of the tax-growth relations. He/she also has to decide how much capital $\left(k_{t+1}\right)$ to be carried forward to the ensuing period. Newly acquired effective labor $\left(H_{t}=n_{t} N_{t} h_{t}\right)$ and physical capital $\left(k_{t}\right)$ accumulated from the previous period are supplied to the labor and capital markets in each period at the prevailing competitive wage $\left(w_{1}\right)$ and rental $\left(r_{t}\right)$ rates. Implicit in the specification of effective labor $\left(H_{t}\right)$ as the product of worked hours $\left(n_{1}\right)$, number of workers $\left(N_{t}\right)$, and their human capital level $\left(h_{t}\right)$ is the assumption of perfect substitutability among these three objects in the supply of labor.

The dynamics of the two growth engines ${ }^{1}$ are determined as follows. The schooling activity contributes to human capital growth:

$$
h_{t+1}=B\left(e_{t}^{\gamma}\right) h_{t}
$$

where B is the knowledge efficiency coefficient and $\gamma$ the productivity parameter. The childrearing activity gives rise to population growth:

$$
N_{t+1}=D\left(v_{t}^{\alpha}\right) N_{t}
$$

where $D$ and $\alpha$ are the fertility efficiency coefficient and productivity parameter respectively. One can think of $N_{t+1} / N_{t}$ as one plus the number of children per family (when the number of parents is normalized to unity). The child-rearing cost ( $v)$ is increasing with the number

\footnotetext{
${ }^{1}$ While both human capital accumulation and population growth can drive growth in total income in the long run, only the former can sustain growth in per capita income.
} 
of children. Dva is therefore the inverse function of this cost-quantity relation. $v$ will be assumed fixed and given when we consider the case of exogenous population growth.

Final output is produced by competitive firms using physical capital $\left(K_{\mathbf{t}}=\mathbf{N}_{\mathbf{l}} \mathbf{k}_{\mathbf{q}}\right)$ and total effective labor $\left(H_{t}\right)$ via a Cobb-Douglas-type technology: $Y_{t}=A K_{t}^{c} H_{t}^{1-c}$, where $A$ is the production coefficient and $\epsilon$ the output share, of capital. Goods produced are either consumed by the private sector $\left(N_{t} c_{t}\right)$ and by the government $\left(G_{t}\right)$ or invested in the form of physical capital $\left(\mathrm{K}_{\mathrm{t}+1}\right)$. Hence, we can write the economy-wide resource constraint as:

$$
N_{t} c_{t}+G_{t}+K_{t+1}=Y_{t}=A K_{t}^{e} H_{t}^{1-\epsilon}
$$

For simplicity, full depreciation is assumed for $K_{t}, N_{t}$, and $h_{t}$ in each period.

The fiscal authority levies flat rate taxes on labor income $\left(\tau_{w t}\right)$ and capital income $\left(\tau_{\mathrm{rt}}\right)$ to finance its spending $\left(G_{t}\right)$. Absent deficit finance, the fiscal budget is balanced every period, with the ratio of government expenditure to nationl output $\tau_{\mathrm{t}}=\epsilon \tau_{\mathrm{n}}+(1-\epsilon) \tau_{\mathrm{m}}$. Below, we shall use $\Omega, \Omega_{w}$ and $\Omega_{r}$ to denote the tax wedges $1-\tau, 1-\tau_{w}$ and $1-\tau_{r}$ respectively.

Since every member in the representative household will receive equal treatment and the economy at large is closed to external loans, borrowing and lending at the individual level will be superfluous. The (effective) family budget constraint is thus given by: $N_{t} c_{t}+$ $K_{t+1} \leq \Omega_{w t} w_{t} H_{t}+\Omega_{n} r_{t} K_{t}$. The optimization problem facing the dynastic head is to choose $\left\{c_{t}, e_{t}, n_{t}, K_{t+1}, N_{t+1}, h_{t+1}\right\}_{t=0}^{\infty}$ to maximize (1) subject to (2), (3), and the budget constraint, given $\left\{w_{t}, r_{t}, \Omega_{w t}, \Omega_{\pi t}\right\}_{t=0}^{\infty}$. The firm's problem is to choose the amount of capital (K $\left.K_{t}^{d}\right)$ and effective labor $\left(H_{t}^{d}\right)$ in each period to maximize profit $Y_{t}-w_{t} H_{t}^{d}-r_{t} K_{t}^{d}$, given $w_{t}$ and $r_{t}$. The equilibrium wage rates $\left(w_{t}\right)$ and interest rates $\left(r_{t}\right)$ are determined in the labor and capital markets under market clearing: $n_{t} N_{t} h_{t}=H_{t}^{d}$ and $K_{1}=K_{t}^{d}$. 
The set of first order conditions describing the optimizing behavior of the household and the firm and the market clearing conditions are laid out in Appendix (A1). These conditions naturally describe the competitive equilibrium of our economy. In a technical appendix (available from the authors upon request), we normalize these equations-by detrending all growing variables by their corresponding steady state growth rates-and loglinearize them around the steady state. This generates a system of six first order linear difference equations in the three state variables $\left\{\mathrm{K}_{\mathrm{t+1}}, \mathrm{h}_{\mathrm{t+1}}, \mathrm{N}_{\mathrm{t+1}}\right\}$ and their shadow prices (or costate variables) $\left\{\mu_{\mathrm{k},}, \mu_{\mathrm{h} t}, \mu_{\mathrm{N} t}\right\}$. We choose parameter values similar to those used in our calibration exercise for the open economy model in Section IV. Coupled with the steady state values of the variables in this model, these parameter values are used to compute the eigenvalues of the fundamental matrix that governs the dynamics of the competitive system, and to show that the economy converges locally to this steady state. ${ }^{2}$

Since our main focus is on long run growth, we shall restrict our attention in what follows to the balanced growth path-the special path along which time allocations as well as the rates of growth of all other variables are constant (so that ratios among these variables defined in certain ways will also be time-invariant). Along this path, as shown in the appendix, we can reduce the system of steady state equations to two equations in two unknowns, $\mathrm{n}$ and $\mathrm{e}$. These two equations can be written as:

where the savings rate (s) and the fiscal wedge $(\Omega)$ are given by The steady state growth rates can be expressed in terms of $e$ and $v$ as: $g_{h}=\mathrm{Be}^{r}-1$ and $g_{N}$

\footnotetext{
${ }^{2}$ Along the lines of King, Plosser, and Rebelo (1987), we show the local (or 'saddle point') stability of the dynamic competitive system by verifying that half of the six eigenvalues lie outside, and the other half on or inside, the unit circle. One of them exactly equals unity, reflecting the (per capita) growth-sustaining property of the human capital engine. This unit root property is common to all endogenous growth models.
} 


$$
\begin{gathered}
\left(\frac{\gamma}{\alpha}\right)\left(\frac{1-n-\epsilon}{e}\right)=1+\left(\frac{\xi}{1-\sigma}-1\right)\left[\frac{(1-s) \Omega}{(1-\epsilon) Q_{w}}\right] \text {, and } \\
\gamma\left(\frac{n}{e}\right)=\frac{\epsilon Q_{r}}{s}-1, \\
s=\frac{\beta \epsilon Q_{r}}{\left(D v^{\alpha}\right)^{\xi}(B e \eta)^{1-\sigma}} \text { and } Q=\epsilon \Omega_{r}+(1-\epsilon) \Omega_{w} .
\end{gathered}
$$

$=D v^{a}-1$, with $g_{c}=g_{y}=g_{h}$ and $g_{K}=g_{Y}$. Here, $g_{x}$ denotes the growth rate of variable $x$ between two periods, $Y$ the total GDP, and $y$ the per capita GDP (so that $y=Y / N$ ).

Equation (5) governs the allocation of time between the child-rearing and education activities, while equation (6) determines the time allocation between work and human capital formation. When population growth is exogenous, the time allocated to child-rearing (v) is fixed, so that equation (5) becomes irrelevant. Note that taxes do not enter equation (6), the only relevant equation that remains: taxes will drop out from the right hand side of (6) upon simplification). Consequently, changes in government tax policy will not have any long term growth effects in this economy. The reason why labor income taxes do not have effects on long run growth can be understood from Boskin's (1975) argument: increase in the constant tax rate on labor income along the balanced growth path will reduce both the returns and costs of investment in human capital equally at the margin, and thus have no impact on the allocation of time between work and education. It turns out that, in our example economy, capital income taxes do not have effects on time allocations, hence growth, either. They do have effects, though, on savings and capital accumulation.

To see how the incorporation of endogenous population growth makes a difference 
to the tax-growth relation, let us now assume that $v$ is endogenously determined. To simplify the story, suppose instead that the time allocated to work (n) is fixed. Then equation (6) becomes irrelevant, and equation (5) remains as the only time allocation equation. Note the dependence of the time allocations and the growth rates on the preference of the agent towards child quantity relative to quality (reflected by $\xi /(1-\sigma)$ ) and the effectiveness of time in producing quantity relative to quality (reflected by $\alpha / \gamma$ ).

To examine the growth effects of tax changes, let us consider two simple policy experiments. $^{3}$ (i) Change in income taxes under uniform taxation of labor and capital incomes with compensating change in the output share of the government (i.e., $\tau_{w}=\tau_{r}=$ ); and (ii) change in the capital income tax rate $\left(\tau_{\mathrm{r}}\right)$ compensated by a change in the labor income tax $\left(\tau_{w}\right)$, keeping $\tau$ constant. Comparative statics show that $e$, hence $g_{h}$, is decreasing (increasing) in $\tau_{\mathrm{r}}$ as $\xi>(<) 1-\sigma$ under the first experiment, and the reverse is true under the second experiment. One can relate these effects to the tradeoff between the quantity and quality of children a la Becker and Lewis (1973). Other things equal, an increase in $\tau_{\mathrm{r}}$ will discourage investment in physical capital and encourage investment in child quantity if people are more biased in their preference towards quantity than quality $(\xi>1-\sigma)$ or investment in child quality in the opposite case $(\xi<1-\sigma)$. As $\tau_{w}$ increases, however, investment in both child quality and child quantity will be discouraged since the returns from both types of investment depend on the future stream of after-tax wage earnings. But the returns from investment in quantity depend also on the utility gain net of

\footnotetext{
${ }^{3}$ Two special cases are worth noting, viz., equal emphasis on 'quality' and 'quantity' of children: $\xi=1-\sigma$ and absence of physical capital: $\epsilon=0$. In both cases, taxes do not have growth effects. In the latter case, there is no transitional dynamics: the economy always grows along the balanced path.
} 
the cost of raising an additional child, which will be $\underset{z}{0}$ as $\xi \gtrless 1-\sigma .{ }^{4}$ 'Quantity' investment will thus become more (less) favorable relative to 'quality' investment as $\xi>(<) 1-\sigma$ as a result of the tax increase. Piecing these arguments together confirms the result under experiment (i) when the increase in $\tau_{r}$ is accompanied by an equal increase in $\tau_{w}$. But if the increase in $\tau_{\mathrm{r}}$ is accompanied by a reduction in $\tau_{\mathrm{w}}$ the argument for $\tau_{\mathrm{w}}$ above will have to be reversed, with the $\tau_{w}$-effect dominating the $\tau_{r}$-effect, to obtain the result under experiment (ii).

This closed economy model has highlighted two main points: (1) the importance of the endogeneity of population growth in the analysis of the long run relation between taxes and growth; and (2) the importance of the relative preference bias between the quality and quantity of children for the effects of tax changes on the two engines of long run growth, viz., human capital growth and population growth. These two points will be sharpened in an open economy setup in the following section.

Since the open economy analysis below will rely heavily on what the after-tax rate of return on capital $\left(F=\Omega_{r}\right)$ is, let us derive it for this simple example. The following fundamental equation can be obtained from the condition for the intertemporal choice of consumption (see (C1) and (C4) in Appendix (A1)):

$$
\left(1+g_{N}\right)^{1-\xi}\left(1+g_{y}\right)^{0}=\beta \bar{r},
$$

where we have made use of the long run equality between $g_{c}$ and $g_{y}$. Given the direct link

4The utility gain from 'quantity' investment net of the gain from 'quality' investment is given by:

$$
\mu_{N_{t}} N_{t+1}-\mu_{m t} h_{t+1}=\left(\frac{\xi}{1-\sigma}-1\right) \sum_{j=t+1}^{m} \beta^{j-t} N_{j}^{\xi} c_{j}^{1-\sigma}
$$


between $g_{N}$ and $g_{y}$ on the one hand and $v$ and $e$ on the other, $I$ can be solved from equation (7) once $v$ and $e$ are determined from equations (5) and (6).

In the following, we shall complicate the story by opening many economies (each similar to the one described above, but with possibly different initial endowments and income tax rates) to capital flows across national boundaries, and consider the implications of capital mobility and national tax policies for growth across countries. We shall use $\tau_{\mathrm{rDt}}^{\mathrm{i}}$ to denote the tax rate on the domestic-source capital income of residents of country $i, r_{\mathrm{rNt}}^{i}$ the tax rate on the capital income earned by non-residents in country $i$, and $\tau_{\mathrm{rFt}}^{i}$ the tax rate on the foreign-source capital income (net of non-residents' taxes paid to the foreign government) of country i residents. The mnemonics are such that ' $D$ ' stands for domesticsource, ' $F$ ' for foreign-source, and ' $N$ ' for non-residents.

\section{The Tax-Growth Relation in the Open Economy}

\section{III.A Capital Mobility}

Consider now the open economy where capital is freely mobile. Abstracting for the moment from tax considerations, the law of diminishing returns implies that capital will move from capital-rich (low marginal product of capital, henceforth, MPK) countries to capitalpoor (high MPK) countries. Over time, such cross-border capital flows will equalize the MPKs prevailing in all countries. In the short run, such capital movement may shorten or lengthen the transition paths of the two countries relative to their autarky transition paths. ${ }^{5}$

\footnotetext{
${ }^{5}$ Barro, Mankiw, and Sala-i-Martin (1992) addresses exactly this issue, i.e., how capital mobility affects the speed of converging from the transition path to the steady state growth path. In the context of our open economy model, it is straightforward to extend the stability analysis for the closed economy (see the discussion on p.5-6 and footnote 2 above) to show that the global economy also converges locally to its balanced growth
} 
In the long run, an empirically relevant steady state world equilibrium will involve positive net capital flows from some countries to some other countries. ${ }^{6}$

To understand how capital mobility may affect long term growth rates across countries, we have to be more specific about what we mean by the long run. We shall follow the convention in the growth literature and identify long run growth with balanced or steady state growth. An implication of the definition of balanced growth is that, along this growth path, with positive net capital flows across countries, the growth rates of total GDP (but not necessarily per capita GDP) must be equal across countries. These positive net steady state capital flows from one country to another are essentially the offset of the debt accumulated over the transition period by the former (i.e., capital-exporting) country. The intuition behind the total growth rates equalization result is that, along the balanced path, the steady state debt payment of one country must grow at the same rate as its total income and the steady state debt receipt of the other country must also grow at the same rate as

path worldwide. In this case, we have 12 eigenvalues corresponding to the 6 states and 6 costates (3 and 3 for each country respectively) under the approximately linear dynamical system. Using the calibrated model described in the next section and Appendix (A2), we verify that half of these eigenvalues lie outside, and half of them on or inside, the unit circle. Two of them (associated with the human capital engines in the two countries) exactly equal unity.

${ }^{6}$ Without further restrictions, two other situations are possible in the long-run: (a) all capital in the world resides in one single country; and (b) no cross-border capital flows (i.e., back to autarky). Both are unrealistic cases. We shall make some assumptions to eliminate these possibilities? Case (a) will not occur if the MPK becomes infinitely high when the capital remaining in any capital-exporting country gets sufficiently small (i.e., the Inada conditions can rule out this corner solution). Case (b) will not occur as long as the countries are heterogeneous in some key fundamentals. If they were homogeneous in all respects, capital flows would not have taken place in the first place. Since our paper focuses on the effects of taxes on growth, let us assume that asymmetry in capital income tax rates is the factor that first induced cross-border capital flows. Suppose further that these countries were travelling along their steady state growth paths initially. Should these taxes remain different, the driving force that initiated capital movement to begin with will again be active if the countries revert to their long run autarky growth paths. As such, (b) can also be ruled out. The only empirically interesting case that remains is the one that involves non-zero flows. In that case, we should expect the direction of capital flows to be from low after-tax MPK countries to high after-tax MPK countries. 
its income. In equilibrium, the debt receipt of one country equals the debt payment of the other, hence the equalization of their total GDP growth rates. ${ }^{7}$ Since total GDP growth equals the sum of per capita GDP growth and population growth, this implies that whether the growth rates of per capita incomes are endogenously determined to be equal across countries hinges on the endogeneity of population growth.

Quite apart from the question whether taxes can potentially affect growth rates in the absence of endogenous population decisions (they are not affected in our autarky model, see previous section), whether they affect the disparity between the long term rates of growth of per capita incomes across countries will also depend crucially on the endogeneity of population growth. With total growth equalization, modelling population growth as an exogenous process leaves no room for taxes to affect per capita growth rates in the long run-when $\left(1+g_{y}^{A}\right) /\left(1+g_{y}^{B}\right)=\left(1+g_{N}^{B}\right) /\left(1+g_{N}^{A}\right)$ for any two countries $A$ and $B$, irrespective of the tax regimes in each country. This is not to say that taxes cannot affect the growth rates of per capita income under exogenous population growth. What it really means is either of the following: (a) the growth effects of taxes are restricted to obey some specific condition-viz., $d g_{y}^{A} / d \tau_{j}^{i}=\left[\left(1+g_{N}^{B}\right) /\left(1+g_{N}^{A}\right)\right]\left(d g_{y}^{B} / d \tau_{j}^{i}\right)(i=A, B ; j=w, r) ;$ or (b) asymmetry in taxes steers the countries away from the trajectory that directs them to their balanced

\footnotetext{
${ }^{7}$ Since per capita income equals total income divided by the size of the population, we can decompose the total income growth rates into the per capita income growth rates and population growth rates: $\left(1+g_{Y}\right)=$ $\left(1+g_{N}\right)\left(1+g_{y}\right)$. With equalization of total income growth across countries, this decomposition implies that $\left(1+g_{N}^{A}\right)\left(1+g_{y}^{A}\right)=\left(1+g_{N}^{B}\right)\left(1+g_{y}^{B}\right)$. Two empirical implications follow:

(1) Long-term rates of growth of population and per capita incomes should be negatively correlated across countries; and

(2) Total income growth rates should exhibit less variation than per capita income growth rates across countries.

Some empirical support for these implications is provided by Razin and Yuen (1994a,1994b).
} 
growth paths.

\section{III.B International Capital Taxation}

When capital is mobile, the choice of international tax principle and tax rates levied on capital incomes earned by residents and non-residents at home and abroad will affect the after-tax rates of return on capital ( $\bar{T}$ ) and, indirectly, the rates of growth of per capita income and population ( $g_{y}$ and $g_{N}$ ) across countries through the fundamental equation (7) specified in Section II. Applied to two open economies (A and B) and imposing the total income growth equalization result together with the no-arbitrage condition between investing capital at home and abroad, ${ }^{8}$ we have, along the balanced path,

$$
\left(\frac{1+g_{y}^{A}}{1+g_{y}^{B}}\right)^{E-(1-0)}=\frac{F^{A}}{\bar{r}^{D}}=\frac{\left(1-\tau_{r D}^{A}\right) r^{A}}{\left(1-\tau_{r F}^{B}\right)\left(1-\tau_{r N}^{A}\right) r^{A}} .
$$

This equation shows how the relative growth rates of per capita incomes in A and B depend on the capital tax rates in the two countries and the relative bias in preference towards quantity versus quality of children $(\xi$ versus $1-\sigma) . A$ priori, the reader may be tempted to think that no-arbitrage restrictions will force the after-tax rates of return on capital ( $\mathrm{I}$ 's) to be equalized across countries under perfect capital mobility, implying

${ }^{8}$ The after-tax rate of return on capital in country $i, r^{i}$, equals $\left(1-\tau^{i}\right) r^{j}$ if capital is invested at home, and $\left(1-r_{\mathrm{rF}}^{i}\right)\left(1-r_{\mathrm{rN}}^{j}\right) \mathrm{r}^{j}$ if capital is invested abroad. Equality between these two rates of return is ensured by the absence of arbitrage opportunities. Our multiplicative specification of double taxation on foreign-source capital income implies that non-residents's capital taxes paid to the foreign government by home residents are deducted from their foreign-source capital income tax base in the home country, i.e., the deduction system. The alternative additive specification $\left(1-r_{\mathrm{rF}}^{i}-\tau_{\mathrm{rN}}^{j}\right) \mathrm{r}$ is actually more in line with the credit system. The reader can, however, rest assured that the results in this paper carry over straightforwardly to the latter specification. 
convergence in both the per capita and total income growth rates. In fact, this reasoning is true only under the source or territorial tax principle, whereby all types of income originating in the country are taxed uniformly regardless of the place of residence of the income recipients. In this case, $\tau_{\mathrm{rFt}}^{\mathrm{i}}=0$ and $\tau_{\mathrm{rNt}}^{\mathrm{i}}=\tau_{\mathrm{rDb}}^{\mathrm{i}}$, implying $\mathrm{r}^{\mathrm{A}}=\mathrm{P}^{\mathrm{B}}$, hence $\mathrm{g}_{\mathrm{y}}^{\mathrm{A}}=\mathrm{g}_{\mathrm{y}}^{\mathrm{B}}$. Under the alternative residence or worldwide principle, residents are taxed on their worldwide income uniformly regardless of the source of income, while nonresidents are not taxed on income originating in the country. In that case, $\tau_{\mathrm{rNt}}^{\mathrm{i}}=0$ and $r_{\mathrm{rFt}}^{\mathrm{i}}=\tau_{\mathrm{rDt}}^{\mathrm{i}}$ so that domesticsource and foreign-source incomes receive identical tax treatment for residents within each country, but asymmetric treatment across countries if different countries levy different capital income tax rates. International asymmetry in F's (due to such asymmetric tax treatments) implies, in turn, asymmetry in growth rates (i.e., $\boldsymbol{T}_{\mathrm{rD}}^{\mathrm{A}} \neq \tau_{\mathrm{rD}}^{\mathrm{B}}$ implies $\mathrm{r}^{\mathrm{A}} \neq \mathrm{F}^{\mathrm{B}}$, hence $\mathrm{g}_{\mathrm{y}}^{\mathrm{A}} \neq$ $\mathrm{g}_{\mathrm{y}}^{\mathbf{B}}$ ).

Equation (8) also indicates that under residence-based taxation, when $\xi * 1-\sigma$, asymmetric tax rates may have differential effects on the growth of per capita income and population. In particular, when people are more biased towards quality than quantity $(\xi<$ $1-\sigma)$, the country with a higher capital tax rate will exhibit faster growth in per capita income and slower growth in population. ${ }^{9}$ The reverse is true when people are more biased towards quantity than quality $(\xi>1-\sigma)$. The intuition is similar to the one given in the closed economy example. Other things equal, the country with a higher capital tax rate will have less incentive to invest in physical capital and more to invest in child quality if $\xi<1-\sigma$

\footnotetext{
${ }^{9}$ The tax rate $\tau_{r}$, rather than the after-tax MPK, matters here because the cross-country MPKs will be equalized under the residence principle anyway.
} 
or in child quantity if $\xi>1-\sigma$. We summarize these results in the following proposition. ${ }^{10,}$

\section{Proposition: International Capital Taxation and Long Run Growth}

When both countries adopt the source principle, $g_{y}^{A}=g_{y}^{B}$ and $g_{N}^{A}=g_{N}^{B}$ if $\xi \sim 1-\sigma$ irrespective of international tax differences. When both countries adopt the residence principle, $g_{y}^{A} \gtrless g_{y}^{B}$ and $g_{N}^{A} \lesseqgtr g_{N}^{B}$ as $r_{r D}^{A} \leqq \tau_{r D}^{B}$ if $\xi>1-\sigma$, and $g_{y}^{A} \xi g_{y}^{B}$ and $g_{N}^{A} \gtreqless g_{N}^{B}$ as $\tau_{r D}^{A} \leqq \tau_{r D}^{B}$ if $\xi<1-\sigma$.

When people are indifferent between quality and quantity (i.e., $\xi=1-\sigma$ ), we require $\tau_{r D}^{A}=\tau_{r D}^{B}$, so $\left(1+g_{N}^{A}\right)\left(1+g_{y}^{A}\right)=\left(1+g_{N}^{B}\right)\left(1+g_{y}^{B}\right)$, for the existence of balanced growth under the residence principle. This condition is not needed, however, under the source principle. While asymmetry in tax rates can induce differential growth rates when both countries ${ }^{10}$ Rebelo (1991,1992) was probably the first one to note that tax-driven growth differentials can survive
in the presence of international capital markets under the worldwide tax system. But since he implicitly
assumes exogenous fertility and identical population growth rates across countries and makes no distinction
between short and long runs (given his 'Ak' economy always grows along the balanced path), the following
possibilities are simply dismissed in his analysis: (i) the asymmetric impact of taxes on the growth of human
capital versus population and the growth of total income versus per capita income, and (ii) the cross-country
disparity in growth rates along the transition path under the source principle. Besides, the pre-tax MPK is
unalterable by capital taxes and the Inada condition does not hold in his 'Ak' economy, so capital (hence,
production) in the whole world will reside in the country with the lowest capital tax rate under the territorial
tax system. In this case, GDP in the rest of the world will be zero, and obviously their GNP growth rates will
be identical to that in the country with the lowest tax rate. For this reason, our result regarding the
equalization of cross-country total GDP growth can be modified to incorporate the possibility of zero net
capital flows in the 'Ak' model. GDP there has to be replaced by GNP, though. In our case, capital will not
necessarily flow towards the low-tax country if the after-tax rate of return on capital abroad is no higher than
that at home as, for instance, when the low-tax country is initially endowed with a huge amount of physical
capital (so that its pre-tax rate of return can be so low that its post-tax return will also turn out to be low
despite the low tax rate). We can thus view Rebelo's example as a limiting case of our more general setup.
11 Jones and Manuelli (1990) also give an example where the tax-driven growth diversity can be preserved
in an open economy. Their example is special because the tax principles/policies they consider are so designed
that the resulting equilibrium is autarky (i.e., zero net capital flows). 
adopt the residence principle, we note that asymmetry in the international tax principle (with or without symmetry in tax rates) can also generate disparity in growth rates. In particular, when country A adopts the residence principle and country B adopts the source principle,

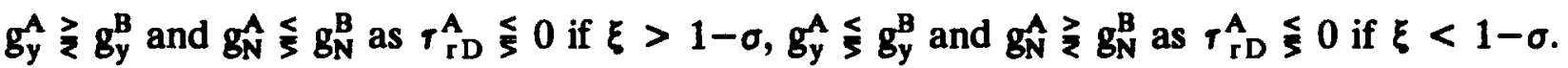
When $\xi=1-\sigma$, balanced growth will not exist unless $r_{r D}^{A}=0 .{ }^{12}$

Our proposition characterizes the tax effects on relative growth due to the relative bias in preference between quantity and quality and the international tax system. To determine whether, in reality, growth rates will more likely be converging or diverging in the face of differential capital tax rates, we display in Table 1 top tax rates and the dominant tax principles (at both the individual and corporate levels) for selected countries with relatively free capital movements.

\section{[insert Table 1 here]}

Evidently, there is a huge disparity in tax rates across countries and the residence principle emerges as the dominant tax principle. The production efficiency, Ramsey (second best) efficiency, and capital export neutrality implications of residence-based taxation may explain its popularity. ${ }^{13}$ As a partial solution to the problem of economic development-the problem of accounting for the observed diversity in the rates of growth of incomes across

\footnotetext{
${ }^{12}$ When $A$ adopts the residence principle and B the source principle, residents of country A will always earn a lower after-tax rate of return-by a factor of $(1-\tau, \mathrm{AD})$-than will residents of country $B$ irrespective of their locations of investment, unless the capital tax rate in $A$ is negative. Residents of country $A$ will earn $\left(1-\tau_{\mathrm{C}}^{A}\right) r^{A}$ at home and $\left(1-\tau_{r F}^{A}\right)\left(1-\tau_{r N}^{B}\right) r^{B}$ abroad, and residents of country $B$ will earn $\left(1-\tau_{r D}^{B}\right) r^{B}$ at home and $r^{A}$ abroad. No arbitrage ensures that $\left(1-r_{r D}^{B}\right) r^{B}=r^{A}$ for residents of both countries. That explains why the sign of $r_{\mathrm{rD}}^{\mathrm{A}}$ rather than the relative size of $\tau_{\mathrm{rD}}^{\mathrm{A}}$ and $\tau_{\mathrm{rD}}^{\mathrm{B}}$ determines the relative growth rates of population and per capita consumption in the two countries.

${ }^{13}$ See Feldstein and Hartman (1979), Gordon (1986), Frenkel, Razin and Sadka (1991) or Razin and Yuen (1992) for a discussion of these implications of the residence principle.
} 
countries-posed by Lucas (1988), we can thus conclude from the proposition that crosscountry asymmetry in capital taxes is a plausible explanation of the diverse growth patterns.

Closer examination of the relation between capital taxes on the one hand and income and population growth rates on the other seems to suggest that $\xi>1-\sigma$ conforms to the situation in these countries. In other words, low capital tax rates tend to be associated with faster growth in per capita income and slower growth in population. This phenomenon is also revealed by the calibration result below.

\section{Calibration and Simulations}

In this section, we attempt to confront the model with data and run simulations in order to quantify the tax-growth relation. In addition, we compare the growth effects of tax changes between closed and open economies in order to assess quantitaively the role of capital mobility.

To better accommodate the data, we employ a slightly richer model than the one spelled out in the previous sections. The additional features of our calibrated model include: (1) the addition of consumption taxes and lump sum transfers, (2) the less than full depreciation of population, physical capital, and human capital, and (3) the utilization of physical capital in the production technology of the education sector.

We lay out in Appendix (A2) the details of the richer model and the set of equations that describes its global steady state growth equilibrium. The model is calibrated to data from the G-7 over the period $1965-87$ by splitting the seven countries into a 'two-country world'-the US versus the other G-6-and imagining that the US and the G-6 were growing 
along their balanced growth paths during this period. We choose benchmark values for the parameters $\left(\beta, \sigma, \xi, \alpha, \epsilon, \gamma, \delta_{k}, \delta_{h}, \delta_{N}, A, B, D\right)$, allocations $\left(c^{i}, n^{i}, e^{i}, \eta^{i}, S^{i j}, S^{j i}, N^{B} h^{B} / N^{A} h^{A}\right)$, growthrates $\left(g_{h}^{i}, g_{N}^{i}\right)$, and policy variables $\left(g^{i}, T^{i}, \tau_{c}^{i}, T_{w}^{i}, \tau_{r D}^{i}, \tau_{r F}^{i}, T_{r N}^{i}\right)$ so that the theoretical equilibrium values of these variables 'match' as closely as possible their long run average values from the data. Long run levels and growth rates data are drawn largely from the 1989 World Development Report, and tax rates data from Mendoza, Razin and Tesar (1993). Some of the parameter values are borrowed from previous empirical studies. Others whose values are less welldocumented, together with some of the variables which do not have direct empirical counterparts, are treated as unknowns and 'estimated' from the steady state equations. In our benchmark case, we assume perfect capital mobility and the international income tax principle is residence-based (given most of the G-7 countries follow the residence principle). The benchmark parameter and initial values are summarized in Table 2 .

\section{[insert Table 2 here]}

We skip the details about our choice of parameter and initial values because, as in many other calibration exercises in the literature, we have achieved only partial success in calibrating our model to data. ${ }^{14}$ In what follows, the reader is welcomed, if he/she so wishes, to interpret what we label as the US and G-6 simply as two artificial economies. The hypothetical experiments described below will then serve as an illustration of the potential

\footnotetext{
${ }^{14}$ As is evident from comparing the numbers in Table 2 with actual data, there is at least three aspects of the data that our model values fail to mimic: (a) the per capita income should be lower in the G-6 than in the US, (b) the output shares of both private and public consumption should be lower in the G-6 than in the US, and (c) the consumption tax rate should be much higher in the G-6 than in the US. The output shares of capital and transfer payments may not match the data very well either. The reported $K / Y$ and $T / Y$ numbers in Table 4 are chosen to satisfy the resource and government budget constraints respectively. The reasons for these discrepancies are obvious: Capital movement between the US and the G-6 is not $100 \%$ free in reality, and capital flows to and from countries other than the G-7 are ignored in our calibration exercise.
} 
quantitative effects of capital mobility and tax changes in an artificial (but hopefully close enough to real) environment.

\section{IV.A Efrect of Capital Mobility}

Our first experiment examines the role of capital mobility. It involves switching from a state where cross-country capital flows are perfectly mobile to a state where capital movements are shut down altogether. The autarky equilibria are computed for the two countries separately under the same parameter and policy settings as in the free mobility case, assuming that lump-sum taxes or subsidies are used to rebalance the fiscal budgets in the absence of foreign-source capital income tax proceeds.

\section{[insert Table 3 here]}

The effects of capital control on growth rate and MPK differentials are intuitively clear. As the numbers on the first rows of the four panels in Table 3 indicate, shutting down capital mobility leads to bigger diversity in cross-country growth rates and rates of return on physical capital. Without capital flows, the pre-tax returns r's, which are equalized under capital mobility and the residence principle, are now different across countries $(\Delta r>0)$, let alone the post-tax returns I's. Not surprisingly, the diversity in both the population and per capita income growth rates widens. The population growth rate rises from $1.30 \%$ to $1.37 \%$ in the US, and falls from $.83 \%$ to $.79 \%$ in the G-6, leading to an increase in the population growth rate differential from $.47 \%$ to $.58 \%$. On the other hand, the per capita income growth rate drops from $1.80 \%$ to $1.66 \%$ in the US, and rises from $2.28 \%$ to $2.35 \%$ in the G-6. The per capita income growth differential therefore grows from $.48 \%$ to $.69 \%$. Under 
capital controls, total GDP growth rates need not be equal across countries. The total income growth rates diverge from the uniform rate of $3.12 \%$ under capital mobility to $3.05 \%$ in the US and 3.16\% in the G-6. Losing the opportunity to channel savings abroad, the G-6 devotes them back to domestic production, causing a rise in both the long run level and rate of growth of per capita GDP. The reverse is true in the US, the capital-importing country before the imposition of capital controls. Without computing the welfare changes due to capital mobility, we can infer that restrictions on capital flows will give rise to welfare losses for both countries simply by observing that autarky is feasible but not chosen by agents in the two countries under the global free capital mobility equilibrium.

\section{IV.B Effect of Capital Income Tax Reform}

The second experiment demonstrates the effects of changes in the capital income taxes. By capital income tax reform, we mean altering the tax rate on capital income with compensating changes in lump-sum taxes to balance the fiscal budgets. We continue to assume the residence principle under capital mobility so that $r_{r}^{i}(i=A, B)$ in the first two panels of Table 3 refers to both $\tau_{\mathrm{rD}}^{\mathrm{i}}$ and $\tau_{\mathrm{rF}}^{\mathrm{i}}$ (with $\tau_{\mathrm{rN}}^{\mathrm{i}}=0$ ). Only very small tax changes are considered in the perfect-capital-mobility (PCM) case because, given the complexity and nonlinearity of the equations, the GAUSS equation solver we use for our simulations breaks down easily for larger deviations from the initial steady state. Relatively bigger tax changes are considered, however, in the no-capital-mobility (NCM) case for two reasons. Computationally, the lower dimensionality of the autarky equilibrium allows us to examine bigger changes. Besides, the growth rate changes resulting from a change in the capital tax 
of the same order of magnitude as in the PCM case are negligible, almost totally unnoticeable. This suggests that the growth effects due to changes in capital taxes are much bigger with than without capital mobility: .004 of a one percent change in $\tau_{r}$ under PCM approximates the growth effect of a one percent change in $\tau_{\mathrm{r}}$ under NCM. Note also that there exists cross-country spillovers of growth effects under PCM, but tax changes in one country will have no effect on the growth rates in the other country under NCM. Without opening the economy, the recent growth literature may thus have substantially underestimated the potentially large growth effects due to tax changes and cross-border policy spillovers.

A few remarks on the implications of capital tax reforms in the two countries for population and income growth and the diversity in these growth rates are in order.

(1) The effects of lowering capital taxes on the growth of population, per capita and total incomes are asymmetric and non-monotonic in the US (the high- $\tau_{\mathrm{r}}$ country) and the G-6 (the low- $\tau_{\mathrm{r}}$ country) under PCM, but symmetric and monotonic under NCM. In the PCM case, a reduction in $\tau_{r}^{A}$ will stimulate an increase in $g_{N}^{A}$ and a fall in $g_{y}^{A}$ and $g_{Y}^{A}$. Opposite changes in $g_{N}^{B}, g_{y}^{B}$, and $g_{Y}^{B}$ occur initially in response to a fall in $r_{r}^{B}$, but these changes can be reversed for further tax reduction. In the $\mathrm{NCM}$ case, $\mathrm{g}_{\mathrm{N}}$ will fall and $\mathrm{g}_{\mathrm{y}}$ and $\mathrm{g}_{\mathrm{Y}}$ rise following a decrease in $\tau_{r}$ These seemingly weird results can be understood in terms of the response of $r$ to changes in $\tau_{r}$. Recall that $F=\left(1-\tau_{r}\right)\left(M P K-\delta_{k}\right)$. Since $1-\tau_{r}$ rises and MPK falls-due to the stimulative effect of tax reduction on capital accumulation and diminishing marginal productivity-when $\tau_{r}$ is lowered, the effect on $r$ is unclear in general. This is reminiscent of the Laffer Curve, which can be multi-modal in our setup. The differential 
effects of tax rate changes on the growth of population $\left(g_{N}\right)$ and per capita income $\left(g_{y}\right)$ are a consequence of our benchmark parameter restriction, viz., $\xi>1-\sigma$.

(2) There is positive co-movement of the various growth rates in the US and G-6 under

PCM. This is because both countries are exposed to the same (physical capital) investment opportunities under capital mobility and the residence principle. In the absence of policy spillovers, no such co-movement exists in the NCM case.

(3) The growth rate differentials $\Delta g_{N}, \Delta g_{y}$ and $\Delta g_{Y}$ may not necessarily be narrowed as the capital tax rates in the two countries get closer. This is not a violation of our proposition, which only predicts the signs, but not also the sizes, of these gaps. In fact, these growth rate gaps will not be closed even if the two countries have identical capital tax rates because what really matter are the after-tax rates of return on capital r's (not the tax rates themselves), and these r's will not be equalized because the consumption and labor income taxes are different across countries.

\section{IV.C Effect of International Income Tax Principle}

In yet another experiment (not shown), we switch the international income tax rule from the residence principle to the source principle. As suggested by our proposition, the population, per capita and total income growth rates are symmetric across countries despite capital tax asymmetries. So are the post-tax returns I's, implying efficiency in the allocation of world savings. The Ramsey (and production) inefficiency of the source principle, however, results in welfare losses for both countries relative to the residence principle. 


\section{Conclusion}

In this paper, we deal with the effects of capital taxation on long term growth. The crucial importance of the endogeneity of population decisions and open economy considerations for the tax-growth relation is highlighted. Although our main focus is on the growth effects of capital taxation under capital mobility, endogenous population is introduced as a salient feature of our analysis. This is because, if population growth is determined exogenously, the long run growth rates of total incomes will have to be equal across countries, which implies certain specific relations among the long run rates of growth of per capita incomes across countries, regardless of their respective capital income tax rates. As our analysis in Section II makes clear, the assumption of endogenous population also opens up the possibility for tax policies to affect the growth rates of aggregate and per capita incomes differently.

In the open economy, we find that the differential growth effects on population and per capita income due to the different rates of taxes on capital income across countries depend on the principle of international taxation (source versus residence) and the preference bias between child quantity and child quality. Supportive evidence for these findings is provided through numerical simulation. We discover relatively large effects of capital income taxes on long term growth of per capita income under free capital mobility. For example, in most of the simulations, a one thousandth of one percent cut in the capital income tax rate leads to almost one hundredth of one percent change in the growth of per capita income. Shutting off capital flows completely reduces the growth effects substantially: four thousandth of a one percent change in the capital income tax rate in the open economy 
approximates the growth effect of a one percent change in the same tax rate in the closed economy. Our numerical results show that the effect on long run growth due to tax changes can be magnified significantly by cross-border capital flows and international policy spillovers. But the growth effects due to complete liberalization of capital flows alone may not be very sizable.

The exploratory nature of our analysis leaves plenty of room for future extensions. Incorporating some forms of capital controls into our theoretical framework will match it better to real world data in the calibration exercise. Econometric estimation of the unknown parameters can also reduce the degree of arbitrariness that calibration entails. In order to improve our understanding towards the effects of various factors affecting growth and development, we may want to expand the sample of countries and consider perhaps the LDCs versus the DCs (less similar economies) rather than the US versus the G-6 (more similar economies). Regarding the policy experiments, other kinds of changes such as the consumption tax reform, labor income tax reform, population control, with and without international policy coordination are of interest. Yet another extension is to compute the transitional dynamics for the evaluation of policy effects in both the short and long runs and for welfare calculations.

While the first generation of endogenous growth models focuses on the sources and mechanisms that can generate sustainable long run growth, the second generation attempts to examine more closely the growth effects of government policies. This paper can be viewed as an effort to push the latter intellectual endeavor a step further. 
Auerbach, A.J. and L.J. Kotlikoff, 1987, Dynamic Fiscal Policy (Cambridge University Press, Cambridge).

Barro, R.J., N.G. Mankiw, and X. Sala-i-Martin, 1992, Capital Mobility in Neoclassical Models of Growth, NBER Working Paper Series No. 4206.

Becker, G.S. and H.G. Lewis, 1973, On the Interaction between the Quantity and Quality of Children, Journal of Political Economy 81, S279-88.

Becker, G.S., K.M. Murphy, and R. Tamura, 1990, Human Capital, Fertility, and Economic Growth," Joumal of Political Economy 98, S12-S37.

Boskin, M.J., 1975, Notes on the Tax Treatment of Human Capital, NBER Working Papers Series No. 116. 1978, Taxation, Saving and the Rate of Interest, Joumal of Political Economy $86,53-27$.

Chamley, C., 1981, The Welfare Cost of Capital Income Taxation in a Growing Economy, Joumal of Political Economy 89, 468-96.

Feldstein, M.S., 1978, The Welfare Cost of Capital Income Taxation, Joumal of Political Econoiny 86, S29-58.

and D. Hartman, 1979. The Optimal Taxation of Foreign-Source Investment Income, Quarterly Joumal of Economics 93, 613-24.

Frenkel, J., A. Razin, and E. Sadka, 1991, Intermational Taxation in an Integrated World. (MIT Press, Cambridge).

Gordon, R.H., 1986, Taxation of Investment and Savings in a World Economy, American Economic Review 76, 1087-1102.

Jones, L.E. and R.E. Manuelli, A Convex Model of Equilibrium Growth, Joumal of Political Economy 98, 1008-38.

Judd, K.L., 1987, The Welfare Cost of Factor Taxation in a Perfect Foresight Model, Joumal of Political Economy 95, 675-709.

King, R.G., C.I. Plosser, and S.T. Rebelo, 1987, Production, Growth, and Business Cycles: Technical Appendix," unpublished manuscript.

King, R.G. and S.T. Rebelo, 1990, Public Policy and Economic Growth: Developing Neoclassical Implications, Joumal of Political Economy 98, S126-49.

Lucas, R.E., Jr., 1988, On the Mechanics of Economic Development, Joumal of Monetary Economics 22, 3-42. 1990, Supply Side Economics: An Analytical Review, Oxford Economic Papers 42, 293-316.

Mendoza, E.G., A. Razin, and L.L. Tesar, 1993 , A Comparative Analysis of the Structure of Tax Systems in Industrial Countries," IMF Working Paper No. 93/14 (forthcoming, Journal of Monetary Economics).

Razin, A. and C.-W. Yuen, 1992, Convergence in Growth Rates: The Role of Capital Mobility and International Taxation, NBER Working Paper Series No. 4214.

, 1994a, Factor Mobility and Economic Growth: Tax-Driven Divergence, unpublished manuscript. 1994b, Capital Mobility and Income Convergence: New Evidence, unpublished manuscript.

Rebelo, S.T., 1991, Long Run Policy Analysis and Long Run Growth, Joumal of Political Economy 99, 500-21.

1992, Growth in Open Economies, Camegie-Rochester Conference Series on Public Policy 36, 5-46.

Summers, L.H., 1981, Capital Taxation and Accumulation in a Life Cycle Growth Model, American Economic Review 71, 533-44. 


\section{APPENDIX}

(A1) Equilibrium Conditions and Derivation of Equations (5) and (6)

The consumer's first order conditions (C) with respect to $c_{t}, e_{t}, n_{t}, K_{t+1}, N_{t+1}$, and $h_{t+1}$ are given by:

$$
\begin{gathered}
N_{t}^{\xi-1} c_{t}^{-\sigma}=\mu_{t}, \\
\mu_{h_{t}} \gamma B e_{t}^{\gamma-1}=\mu_{t} \Omega_{w t} w_{t} N_{t}, \\
\mu_{N_{t}} \alpha D v_{t}^{\alpha-1}=\mu_{t} \Omega_{w t} w_{t} h_{t}, \\
\mu_{t}=\beta \mu_{t+1} \Omega_{r_{t+1}} r_{t+1}, \\
\mu_{h_{t}}=\beta\left(\mu_{h_{t+1}} B e_{t+1}^{\gamma}+\mu_{t+1} \Omega_{w_{t+1}} w_{t+1} n_{t+1} N_{t+1}\right), \text { and } \\
\mu_{N_{t}}=\beta\left[\mu_{N_{t+1}} D v_{t+1}^{\alpha}+\mu_{t+1}\left(\Omega_{w_{t+1}} w_{t+1} n_{t+1} h_{t+1}-c_{t+1}\right)+\left(\frac{\xi}{1-\sigma}\right) N_{t+1}^{t-1} c_{t+1}^{1-0}\right],
\end{gathered}
$$

where $\mu_{1}, \mu_{\mathrm{bl}}$, and $\mu_{\mathrm{Nt}}$ are the Lagrange multipliers ( $\mu$ for 'mu'ltipliers) at time $t$ associated with the consumer budget constraint and the laws of motion of population and human capital respectively. The firm's first order conditions $(F)$ are

$$
\begin{gathered}
w_{t}=(1-\epsilon) A\left(\frac{K_{t}}{H_{t}}\right)^{\epsilon} \text {, and } \\
r_{t}=\epsilon A\left(\frac{K_{t}}{H_{t}}\right)^{\epsilon-1} .
\end{gathered}
$$

The equilibrium conditions in the labor and capital markets (E) are

$$
\begin{gathered}
n_{r} N_{t} h_{t}=H_{t}^{d}, \text { and } \\
K_{t}=K_{t}^{d} .
\end{gathered}
$$


Substituting (2), (3) and (F1) into (C2) and (C3), we get,

$$
\frac{\gamma \mu_{h_{t}} h_{t+1}}{e_{t}}=\frac{(1-\epsilon) \Omega_{w_{t}} \mu_{t} Y_{t}}{n_{t}}=\frac{\alpha \mu_{N_{t}} N_{t+1}}{v_{t}} .
$$

Along the balanced growth path, time allocations and tax rates are constant, i.e., $e_{t}=e_{t+1}, n_{t}=n_{t+1}$, $v_{t}=v_{t+1}, \Omega_{t}=\Omega_{t+1}, \Omega_{w t}=\Omega_{w t+1}$, and $\Omega_{\pi}=\Omega_{\pi+1}$, so that (A1) implies that

$$
\frac{\beta \mu_{h_{t+1}} h_{t+2}}{\mu_{h_{t}} h_{t+1}}=\frac{\beta \mu_{t+1} Y_{t+1}}{\mu_{t} Y_{t}}=\frac{\beta \mu_{N_{t+1}} N_{t+2}}{\mu_{N_{t}} N_{t+1}},
$$

where the three terms in (A2) are given respectively by

$$
\frac{\beta \mu_{h_{t+1}} h_{t+2}}{\mu_{h_{t}} h_{t+1}}=1-(1-\epsilon) \Omega_{w}\left(\frac{\beta \mu_{t+1} Y_{t+1}}{\mu_{h_{t}} h_{t+1}}\right)
$$

from (2), (C5), and (F1),

$$
\frac{\beta \mu_{t+1} Y_{t+1}}{\mu_{t} Y_{t}}=\frac{s}{\epsilon \Omega}
$$

from $(C 1)$ and $(C 3)$, with $s \equiv K_{1+1} / Y_{1}=\beta \varepsilon \Omega_{r} /\left(D v^{\alpha}\right)^{\xi}\left(B e^{\eta}\right)^{1-\alpha}$, and

$$
\frac{\beta \mu_{N_{t+1}} N_{t+2}}{\mu_{N_{t}} N_{t+1}}=1-\left[(1-\epsilon) \Omega_{w}+\left(\frac{\xi}{1-\sigma}-1\right)(1-s) \Omega\right]\left(\frac{\beta \mu_{t+1} Y_{t+1}}{\mu_{N_{t}} N_{t+1}}\right)
$$

from (3), (C1), (C6), and (F1). Combining (A1)-(A4) yields equation (5), while combining (A1)-(A3) and (A5) yields equation (6) in the text. 


\section{(A2) The Calibrated Model and its Steady State Equations}

Let us first describe the additional features in our calibrated model. In the open economy, we need to distinguish between domestic savings and investment. A slightly different notation for savings (in the form of physical capital) is needed, viz., $S_{1}$ instead of $K_{4}$. At the beginning of each period $t$, each agent in country $i$ possesses $S_{1}^{i} / N_{t}^{i}$ of physical capital carried over from the previous period (given $S_{0}^{i} N_{0}^{i}$ at $t=0$ ). Of the capital that is invested at home $\left(S_{1}^{i j} / N_{1}^{i}\right)$, a fraction $\eta_{t}^{i}$ is allocated as inputs to final goods production, and the remaining fraction $\left(1-\eta_{t}^{i}\right)$ to human capital formation. ( $\left(S_{1}^{i j} / N_{t}^{i}\right.$ is capital invested abroad, and $S_{1}^{i}=S_{1}^{i i}+S_{1}^{i j}$.) The amount of physical capital used in the production of individual human capital is thus $k_{h t}^{i}=\left(1-\eta_{t}^{i}\right) S_{i}^{i i} / N_{t}^{i}$. The total amount of physical capital used in the production of final goods is $\eta_{i}^{i} S_{1}^{i i}$, plus the capital imported from abroad $\left(S_{1}^{j i}\right)$, i.e., $K_{y 1}^{i}=\eta_{1}^{i} S_{t}^{i i}+S_{i}^{j i}$. Given this new specification, the human capital production function in equation (2) is rewritten as $B\left(k_{h}\right)^{\gamma}(e h)^{1-\gamma}$, and the $K$ that enters the production function of final goods should be understood as $\mathrm{K}_{\mathrm{y}}$.

To accommodate more realistic rates of depreciation in the calibration, we add $\left(1-\delta_{h}\right) h_{l}$, $\left(1-\delta_{N}\right) N_{t}$ and $\left(1-\delta_{k}\right) S_{t}$ to the right hand sides of equations (2), (3), and (4). The resource constraint in country $i$ is now given by:

$$
N_{t}^{i} c_{t}^{i}+G_{t}^{i}+S_{t+1}^{i}=G N P_{t}^{i}+\left(1-\delta_{k}\right) S_{t}^{i},
$$

where GNP, is the sum of $Y_{1}^{i}$ and the net capital income from abroad, $\left[\left(1-\tau_{t N}^{j}\right)\left(r_{i}^{j}-\delta_{k}\right)+\delta_{k}\right] S_{1}^{j j}-$ $\left[\left(1-\tau_{\mathrm{rN}}^{\mathrm{i}}\right)\left(\mathrm{r}_{\mathrm{i}}^{\mathrm{j}}-\delta_{\mathrm{k}}\right)+\delta_{\mathrm{k}}\right] \mathrm{S}_{\mathrm{t}}^{\mathrm{ji}}$, and we have assumed tax deductibility of depreciation allowances.

We also incorporate taxation on domestic consumption $\left(\tau_{c t}^{i}\right)$ and lump sum transfers $\left(T_{1}^{i}\right)$ into the tax structure to make it more comprehensive.

Since we want to analyze the long run effects of changes in taxes and capital mobility, we shall focus only on steady state behavior. Along the balanced growth path, the time allocations (n,e,v), capital sector-allocation factor $\eta^{i}$, tax rates $\left(\tau_{c}^{i}, \tau_{w}^{i}, \tau_{r D}^{i}, \tau_{r F}^{i}, \tau_{r N}^{i}\right)$ and growth rates $\left(g_{h}^{i}, g_{N}^{i}\right)$ are constant. The following 'ratio' variables will also be time-invariant:

$$
c^{i}=\frac{c_{t}^{i}}{h_{t}^{i}}, S^{i i}=\frac{S_{t}^{i i}}{N_{t}^{i} h_{t}^{i}}, S^{i j}=\frac{S_{t}^{i j}}{N_{t}^{i} h_{t}^{i}}, k_{y}^{i}=\frac{K_{y t}^{i}}{N_{t}^{i} h_{t}^{i}}, k_{h}^{i}=\frac{k_{h t}^{i}}{h_{t}^{i}}, G^{i}=\frac{G_{t}^{i}}{N_{t}^{i} h_{t}^{i}}, T^{i}=\frac{T_{t}^{i}}{N_{t}^{i} h_{t}^{i}}, y^{i}=\frac{y_{t}^{i}}{N_{t}^{i} h_{t}^{i}} .
$$

We can then obtain the following steady state equations.

$$
\begin{gathered}
\frac{\left(1-\tau_{w}^{i}\right)(1-\epsilon) y^{i} / n^{i}}{\left(1-\tau_{r D}^{i}\right) \epsilon y^{i} / k_{y}^{i}+\delta_{k}}=\left(\frac{1-\gamma}{\gamma}\right)\left(\frac{k_{h}^{i}}{e^{i}}\right), \\
\frac{n^{i}}{e^{i}}=\frac{1-\beta^{i}\left(1-\gamma R_{h}^{i}\right)}{\beta^{i}(1-\gamma) R_{h}^{i}},
\end{gathered}
$$




$$
\begin{gathered}
\beta^{i}\left(1+\tau_{c}^{i}\right) c^{i}\left(\frac{\xi}{1-\sigma}-1\right)\left(\frac{\alpha R_{N}^{i}}{1-n^{i}-e^{i}}\right)=\left(1-\tau_{w}^{i}\right)(1-\epsilon)\left(\frac{y^{i}}{n^{i}}\right)\left\{1-\beta^{i}\left[1+\frac{\alpha R_{N}^{i}\left[(1-\gamma) n^{i}-\gamma e^{i}\right]}{(1-\gamma)\left(1-n^{i}-e^{i}\right)}\right]\right\}, \\
\left(1-\tau_{r D}^{i}\right)\left(\frac{\epsilon y^{i}}{k_{y}^{i}}-\delta_{k}\right)=\frac{\left(1+g_{N}^{i}\right)\left(1+g_{h}^{i}\right)}{\beta^{i}}-1=\left(1-\tau_{r F}^{i}\right)\left(1-\tau_{r N}^{j}\right)\left(\frac{\epsilon y^{j}}{k_{y}^{j}}-\delta_{k}\right), \\
g_{h}^{i}=B\left(k_{h}^{i}\right)^{\gamma}\left(e^{i}\right)^{1-\gamma}-\delta_{h}, \\
g_{N}^{i}=D\left(N^{j}\right)^{\alpha}-\delta_{N}, \\
\left.\left.=y^{i}+\left[\left(1-\tau_{r N}^{j}\right)\left(\frac{\epsilon y^{j}}{k_{y}^{j}}-\delta_{k}\right)+\delta_{k}\right] S^{i j}-\left[\left(1+g_{N}^{i}\right)\left(1+g_{h}^{j}\right)-\left(1-\delta_{k}\right)\right] S^{i}+\sigma_{r N}^{i}\right)\left(\frac{\epsilon y^{i}}{k_{y}^{i}-\delta_{k}}\right)+\delta_{k}\right] S^{j i}\left(\frac{N^{j} h^{j}}{N^{i} h^{i}}\right), \\
\tau_{c}^{i} c^{i}+\tau_{w}^{i}(1-\epsilon) y^{i}+\left[\tau_{r D^{i}}^{i} S^{i j} \eta^{i}+\tau_{r N}^{i} S^{j i}\left(\frac{N^{j} h^{j}}{N^{i} h^{i}}\right)\right]\left(\frac{\epsilon y^{i}}{k_{y}^{i}}-\delta_{k}\right)+\tau_{r F}^{i}\left(1-\tau_{r N}^{j}\right) S^{i j}\left(\frac{\epsilon y^{j}}{k_{y}^{j}}-\delta_{k}\right) \\
=g^{i}+T^{i},
\end{gathered}
$$

$$
\begin{gathered}
\text { where } y^{i}=A\left(k_{y}^{i}\right)^{\epsilon}\left(n^{i}\right)^{1-\epsilon}, \quad k_{y}^{i}=\eta^{i} S^{i i}+S^{j i}, \quad k_{h}^{i}=(1-\eta) S^{i i}, \\
\beta^{i}=\beta\left(1+g_{N}^{i}\right)^{\xi}\left(1+g_{h}^{i}\right)^{1-\sigma}, \quad R_{h}^{i}=\frac{g_{h}^{i}+\delta_{h}}{1+g_{h}^{i}}, \quad R_{N}^{i}=\frac{g_{N}^{i}+\delta_{N}}{1+g_{N}^{i}} .
\end{gathered}
$$

The equalization of total growth rates restriction introduces one additional equation that should hold in the long run, i.e.,

$$
\left(1+g_{N}^{A}\right)\left(1+g_{h}^{A}\right)=\left(1+g_{N}^{B}\right)\left(1+g_{h}^{B}\right)
$$

Together, they constitute 19 equations in 19 unknowns, viz., $\left(c^{i}, n^{i}, e^{i}, \eta^{i}, S^{i i}, S^{i j}, g_{h}^{i}, g_{N}^{i}\right)(i=A, B ; j=$ $B, A)$ plus the steady state ratio of 'total' human capitals $N^{B} h^{B} N^{A} h^{A}$ and 2 policy variables, one for each country. (Each policy variable acts as the compensating factor to balance the fiscal budget in its country, given the values of the other policy variables.) 
Table 1 Taxation of Foreign-Source Capital Income-Selected Countries

\begin{tabular}{lllll}
\hline & \multicolumn{2}{c}{ Individual } & & \multicolumn{2}{c}{ Corporate } \\
\cline { 5 - 6 } Country & Top tax & Dominant & Top tax & $\begin{array}{l}\text { Dominant } \\
\text { principle }\end{array}$ \\
& rate (\%) & rate (\%) & principle \\
\hline Belgium & 55 & $\mathrm{R}$ & 43 & $\mathrm{~S}$ \\
Denmark & 68 & $\mathrm{R}$ & 50 & $\mathrm{R}$ (with credit) \\
France & 53 & $\mathrm{R}$ & 39 & $\mathrm{~S}$ \\
Germany & 56 & $\mathrm{R}$ & 56 & $\mathrm{R}$ (with deduction) \\
Greece & 50 & $\mathrm{R}$ & 35 & $\mathrm{R}$ (with credit) \\
Ireland & 58 & $\mathrm{R}$ & 43 & $\mathrm{R}$ (with credit or deduction) \\
Italy & 50 & $\mathrm{R}$ & 46 & $\mathrm{R}$ (with credit) \\
Luxembourg & 56 & $\mathrm{R}$ & 36 & $\mathrm{R}$ (with credit) \\
Netherlands & 72 & $\mathrm{R}$ & 36 & $\mathrm{R}$ (with credit or deduction) \\
Portugal & 40 & $\mathrm{R}$ & 36 & $\mathrm{R}$ (with credit) \\
Spain & 56 & $\mathrm{R}$ & 35 & $\mathrm{R}$ (with credit) \\
United Kingdom & 60 & $\mathrm{R}$ & 35 & $\mathrm{R}$ (with credit) \\
Canada & $42-49^{\mathrm{c}}$ & & 38 & \\
Japan & 50 & & 42 & $\mathrm{R}$ (with credit) \\
United States & $28-38^{\mathrm{d}}$ & $\mathrm{R}$ & 34 & \\
\hline
\end{tabular}

Sources: Lans Bovenberg and George Kopits, "Harmonization of Taxes on Capital Income and Commodivies in the European Community," IMF, October 1989, and Individual Taxes: A Worldwide Summary. Price Waterhouse, 1989.

- The source principle applies under treaties and for substantial participation in foreign companies.

With refund for excess foreign tax credit.

'Including provincial taxes.

'Including state taxes. 
Table 2. Summary of Benchmark Valucs

\begin{tabular}{|c|c|c|}
\hline \multicolumn{3}{|l|}{ Initial steady state values } \\
\hline Per capita output in the US & $y^{\wedge}$ & $1.000(1.000)$ \\
\hline Per capita output in the G-6 & $y^{B}$ & $1.050(0.725)$ \\
\hline Consumption-output ratio in the US & $C^{\wedge} / Y^{\wedge}$ & $0.650(0.660)$ \\
\hline Consumption-output ratio in the G-6 & $\mathrm{C}^{\mathrm{B}} / \mathrm{Y}^{\mathrm{B}}$ & $0.660(0.588)$ \\
\hline Capital-output ratio in the US & $K^{\wedge} / Y^{\wedge}$ & 1.795 \\
\hline Capital-output ratio in the G-6 & $\mathrm{K}^{\mathrm{B}} / \mathrm{Y}^{\mathrm{B}}$ & 1.751 \\
\hline $\begin{array}{l}\text { Ratio of net capital flow from the G-6 to the US } \\
\text { (= US's current account deficits) to US output }\end{array}$ & $S^{A B} / Y^{A}$ & $-0.035(-.035)$ \\
\hline Fraction of capital allocated to goods production in the US & $\eta^{\mathrm{A}}$ & 0.690 \\
\hline Fraction of capital allocated to goods production in the G-6 & $\eta^{\mathrm{B}}$ & 0.714 \\
\hline Fraction of time allocated to goods production in the US & $\mathrm{n}^{\wedge}$ & 0.409 \\
\hline Fraction of time allocated to goods production in the G-6 & $n^{B}$ & 0.430 \\
\hline Fraction of time allocated to human capital formation in the US & $\mathrm{c}^{\wedge}$ & 0.376 \\
\hline Fraction of time allocated to human capital formation in the G-6 & & 0.401 \\
\hline Population growth rate in the US & $\mathrm{g}_{\mathrm{N}}$ & $0.013(0.010)$ \\
\hline Population growth rate in the G-6 & $g_{N}^{B}$ & $0.008(0.006)$ \\
\hline Per capita income growth rate in the US & $g_{y}^{\wedge}$ & $0.018(0.015)$ \\
\hline Per capita income growth rate in the G- 6 & $\mathrm{~g}_{y}^{\mathrm{g}}$ & $0.023(0.028)$ \\
\hline
\end{tabular}

Initial values of policy variables

Output share of government spending in the US

$G^{\wedge} / Y^{\wedge} \quad 0.200(0.210)$

Output share of government spending in the G-6

Ratio of lump-sum transfers to output in the US

$G^{B} / Y^{B} \quad 0.200(0.176)$

$\begin{array}{lll}\mathrm{T}^{\wedge} / \mathrm{Y}^{\wedge} & 0.243\end{array}$

Ratio of lump-sum transfers to output in the G-6

$\mathrm{T}^{\mathrm{B}} / \mathrm{Y}^{\mathrm{B}} \quad 0.168$

Consumption tax rate in the US

Consumption tax rate in the G-6

Labor income tax rate in the US

Labor income tax rate in the G-6

Tax rate on domestic-source capital income of the US residents

Tax rate on domestic-source capital income of the G-6 residents

Tax rate on foreign-source capital income of the US residents

Tax rate on forcign-source capital income of the G- 6 residents

US tax rate on G-6 residents' capital income earned in the US

G-6 tax rate on US residents' capital income carned in the G-6

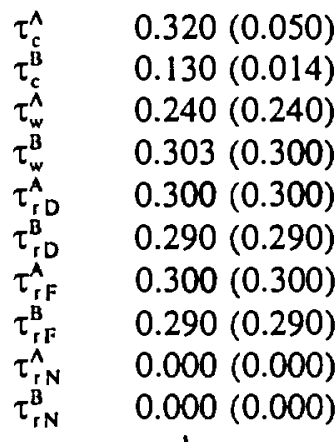

Production parameter values

Capital's share in goods production

$\varepsilon \quad 0.250$

Capital's share in human capital production

$\gamma \quad 0.165$

Fertility productivity parameter

Rate of depreciation of physical capital

Rate of depreciation of human capital

Mortality rate

Output production coefficient

Human capital production cocfficient

Fertility coefficient

$\alpha \quad 1.000$

$\delta_{k} \quad 0.050$

$\delta_{\mathrm{n}} \quad 0.080$

$\begin{array}{ll}\delta_{\mathrm{N}} & 0.009\end{array}$

A $\quad 1.848$

B $\quad 0.245$

D $\quad 0.104$

Subjective discount factor

\section{Preference parameter values}

Inverse of intertemporal elasticity of substitution $\quad \sigma \quad 0.398$

Altruism paramcler

$\xi \quad 0.956$

N.B. Numbers in parenthesis are actual long-run average (1965-87) data for the G-7, whereas all other numbers are calibrated to match closely the data while satisfying all the steady state equations. 
Table 3. Capital Income Tax Reforms with and without Capital Mobility

Perfect Capital Mobility: (a) Reform in the US

\begin{tabular}{|c|c|c|c|c|c|c|c|c|c|c|c|}
\hline$\tau_{r}^{\wedge}$ & $\mathrm{g}_{\mathrm{N}}^{\mathrm{A}}$ & $\mathbf{g}_{\mathrm{N}}^{\mathrm{B}}$ & $\Delta \mathrm{g}_{\mathrm{N}}$ & $g_{y}^{A}$ & $\mathrm{~g}_{y}^{\mathbf{B}}$ & $\Delta g_{y}$ & $g_{Y}^{A}$ & $\mathrm{~g}_{\mathrm{Y}}^{\mathbf{B}}$ & $\Delta \mathrm{g}_{\mathbf{Y}}$ & $\Delta \Gamma$ & $\Delta \bar{T}$ \\
\hline & & & & & & .475 & 3.123 & 3.123 & .000 & & 1820 \\
\hline 29.99 & 1.30 & .835 & -.469 & 1.791 & 2.2 & .474 & 3.119 & & .000 & .0 & .1818 \\
\hline 29.998 & 1.309 & .840 & -.469 & 1.781 & 2.255 & .473 & 3.114 & 3.114 & .000 & .000 & .1816 \\
\hline 29.997 & 1.314 & .845 & -.468 & 1.772 & 2.245 & .473 & 3.109 & 3.109 & .000 & .000 & .1814 \\
\hline 29.996 & 1.318 & .850 & -.468 & 1.762 & 2.235 & .472 & 3.104 & 3.104 & .000 & .000 & .1812 \\
\hline
\end{tabular}

Perfect Capital Mobility: (b) Reform in the G-6

\begin{tabular}{|c|c|c|c|c|c|c|c|c|c|c|c|}
\hline$\tau_{\mathrm{s}}^{\mathrm{B}}$ & $\mathrm{g}_{\mathrm{N}}$ & $\mathrm{g}_{\mathrm{N}}^{\mathrm{B}}$ & $\Delta g_{N}$ & $g_{y}^{A}$ & $\mathrm{~g}_{\mathrm{y}}^{\mathrm{B}}$ & $\Delta g_{y}$ & $g_{Y}^{A}$ & $\mathrm{~g}_{\mathrm{Y}}^{\mathrm{B}}$ & $\Delta g_{Y}$ & $\Delta r$ & $\Delta \overline{\mathrm{I}}$ \\
\hline 8.786 & 1.300 & & -.470 & 1.800 & & .475 & 3.123 & & .000 & .000 & .1820 \\
\hline 28.785 & 1.29 & 0.823 & -.471 & 1.813 & 2.2 & .475 & 3.130 & 3.130 & .000 & & .1823 \\
\hline 28.784 & 1.289 & 0.818 & -.471 & 1.822 & 2.298 & .476 & 3.135 & 3.135 & .000 & .000 & .1826 \\
\hline 28.783 & 1.285 & 0.813 & -.472 & 1.831 & 2.308 & .477 & 3.140 & 3.140 & .000 & .000 & .1828 \\
\hline 28.782 & 1.289 & 0.817 & -.471 & 1.823 & 2.299 & .476 & 3.136 & 3.136 & .000 & .000 & .1829 \\
\hline
\end{tabular}

No Capital Mobility: (a) Reform in the US

\begin{tabular}{|c|c|c|c|c|c|c|c|c|c|c|c|}
\hline$\tau_{r}^{A}$ & $\mathrm{~g}_{\hat{N}}$ & $g_{N}^{B}$ & $\Delta g_{N}$ & $g_{y}^{A}$ & $\mathbf{g}_{y}^{B}$ & $\Delta g_{y}$ & $\hat{g \hat{Y}}$ & $\mathbf{g}_{\mathbf{Y}}^{\mathbf{B}}$ & $\Delta g_{Y}$ & $\Delta r$ & $\Delta \bar{I}$ \\
\hline 1.000 & 1.370 & 0.793 & -.577 & 1.655 & 2.348 & 0.693 & 3.048 & 3.159 & .111 & .127 & .271 \\
\hline .000 & 1.353 & 0.793 & -.560 & 1.696 & 2.348 & 0.652 & 3.072 & 3.159 & .087 & .313 & .254 \\
\hline .000 & 1.335 & 0.793 & -.542 & 1.737 & 2.348 & 0.611 & 3.096 & 3.159 & .063 & .494 & .237 \\
\hline .000 & 1.317 & 0.793 & -.524 & 1.778 & 2.348 & 0.570 & 3.119 & 3.159 & .040 & .670 & .221 \\
\hline 6.000 & 1.300 & 0.793 & -.507 & 1.818 & 2.348 & 0.530 & 3.142 & 3.159 & .017 & .842 & .204 \\
\hline
\end{tabular}

No Capital Mobility: (b) Reform in the G-6

\begin{tabular}{|c|c|c|c|c|c|c|c|c|c|c|c|}
\hline$\tau_{r}^{B}$ & $g_{N}^{A}$ & $g_{N}^{B}$ & $\Delta g_{N}$ & $g_{y}^{A}$ & $g_{y}^{B}$ & $\Delta g_{y}$ & $g_{\hat{Y}}$ & $g_{Y}^{B}$ & $\Delta \mathrm{g}_{\mathrm{Y}}$ & $\Delta r$ & $\Delta \overline{\mathbf{I}}$ \\
\hline 28.786 & 1.370 & 0.793 & -.577 & 1.655 & 2.348 & 0.693 & 3.048 & 3.159 & 0.111 & .127 & .271 \\
\hline 28.000 & 1.370 & 0.779 & -.591 & 1.655 & 2.379 & 0.724 & 3.048 & 3.177 & 0.129 & -.020 & .284 \\
\hline 27.000 & 1.370 & 0.761 & -.609 & 1.655 & 2.419 & 0.764 & 3.048 & 3.198 & 0.150 & -.202 & .300 \\
\hline 26.000 & 1.370 & 0.743 & -.627 & 1.655 & 2.458 & 0.803 & 3.048 & 3.220 & 0.172 & -.379 & 316 \\
\hline 25.000 & 1.370 & 0.726 & -.644 & 1.655 & 2.497 & 0.842 & 3.048 & 3.241 & 0.193 & -.552 & .332 \\
\hline
\end{tabular}

N.B. (i) All entries in the table are in percentage terms (i.e., multiplied by 100); (ii) $\Delta x \equiv x^{B}-x^{\wedge}$ for variable $x$. 